\title{
Microstructure, Mechanical Properties (Strength and Hardness) and Wear Behavior of Chilled Aluminum Alloy (LM-13) Reinforced with Titanium Carbide (TiC) Metal Matrix Composites
}

\author{
Joel Hemanth'1, K. Arasukumar² \\ ${ }^{1}$ School of Engineering, Presidency University, Bangalore, India \\ ${ }^{2}$ Department of Mechanical Engineering, Gopalan College of Engineering and Management, Bangalore, India \\ Email: joelhemanth@hotmail.com
}

How to cite this paper: Hemanth, J. and Arasukumar, K. (2019) Microstructure, Mechanical Properties (Strength and Hardness) and Wear Behavior of Chilled Aluminum Alloy (LM-13) Reinforced with Titanium Carbide (TiC) Metal Matrix Composites. Journal of Materials Science and Chemical Engineering, 7, 55-66.

https://doi.org/10.4236/msce.2019.77007

Received: June 8, 2019

Accepted: July 20, 2019

Published: July 23, 2019

Copyright $\odot 2019$ by author(s) and Scientific Research Publishing Inc. This work is licensed under the Creative Commons Attribution-NonCommercial International License (CC BY-NC 4.0). http://creativecommons.org/licenses/by-nc/4.0/ (c) (i) \& Open Access

\begin{abstract}
This paper deals with the production of aluminum alloy (LM-13) reinforced with titanium carbide ( $\mathrm{TiC}$ ) chilled composites subject to different chilling rates to study the effect of chilling on microstructure, mechanical and tribological behavior. Metallic and non-metallic chills ( $25 \mathrm{~mm}$ thick) were used in this investigation. The specimens taken from casting blocks were tested for their microstructure, strength, hardness and wear behavior. It was found in the present investigation that chilling rate and addition of $\mathrm{TiC}$ reinforcement (3 to $12 \mathrm{wt} \%$ in steps of $3 \mathrm{wt} \%$ ) have improved both mechanical properties (strength and hardness) and wear resistance of the composite developed. Out of the chills used, copper chill was found to be good in improving mechanical properties because of its high Volumetric Heat Capacity (VHC). It is concluded from the above investigation that type of chill and hence chilling rate, reinforcement content have an effect on mechanical properties wear behavior.
\end{abstract}

\section{Keywords}

Wear, Strength, Hardness, Chill, Solidification

\section{Introduction}

Aluminum alloys are known for their strength and ductility. The combination of strength and ductility adds to give aluminum alloy greater values of toughness and resistance to wear. It is well known that properties of $\mathrm{Al}$ alloy can be con- 
trolled by controlling its composition or by adding the reinforcement.

Study on the effect of high rate heat transfer during solidification of $\mathrm{Al}$ alloy using water-cooled and sub-zero chills on mechanical behavior [1] concluded that a number of dendritic cells are significantly larger in the case of chilled composite than that obtained in the case of composite cast without a chill. Dendrite arm spacing was shown to be a major factor that affects ultimate tensile strength and fracture toughness. In another study on microstructure of cryogenically treated $\mathrm{Al}$ alloy [2], it is reported that cryogenic treatment facilitates the formation of fine grain structure and the subsequent alloying improves the wear resistance of $\mathrm{Al}$ composites.

It is well known that $\mathrm{Al}$ alloys that freeze over a wide range of temperature are difficult to feed during solidification [3] [4] [5]. The dispersed porosity caused by the pasty mode of solidification can be effectively reduced by the use of chills. Chills extract heat at a faster rate and promote directional solidification. Therefore chills are widely used by foundry engineers for the production of sound and quality castings. There have been several investigations [6] [7] [8] [9] on the influence of chills on the solidification and soundness of alloys. With the increase in the demand for quality composites, it has become essential to produce $\mathrm{Al}$ composites free from unsoundness.

Hence in the present investigation, the addition of reinforcement, and chilling route during solidification followed by aging were adopted to eliminate micro-porosity and to improve mechanical properties [10] [11].

\section{Relevance of the Present Research}

The objective of the present research is to examine the effect of the addition of reinforcement $(\mathrm{TiC})$ on the microstructure and mechanical properties of chilled aluminum alloy (LM-13). These composites are widely used in the production of automotive parts, aerospace application, structural members, valves, flanges, motor casing, and fittings at high temperature service. Hence in the present investigation effort has been made to enhance the mechanical properties and wear behavior of $\mathrm{Al}$ alloy reinforced with $\mathrm{TiC}$ using a different route by introducing chilling effect during solidification. So for no work has been done on chill treated TiC reinforced composite during solidification. The present work is therefore under taken to fill the void.

\section{Experimental Procedure}

\subsection{Molding, Melting and Casting}

In the present research metallic and non-metallic end chills were used to get test castings. These end chills were fabricated to required size and set in $\mathrm{CO}_{2}$ sand molds (AFS standard size $225 \times 150 \times 25 \mathrm{~mm}$ ) as shown in Figure 1. Zircon sand coating was applied to mold to get good surface finish as well to avoid fusing of sand.

Chills used: 1) Metallic chill (copper).

2) Non metallic chill (graphite). 


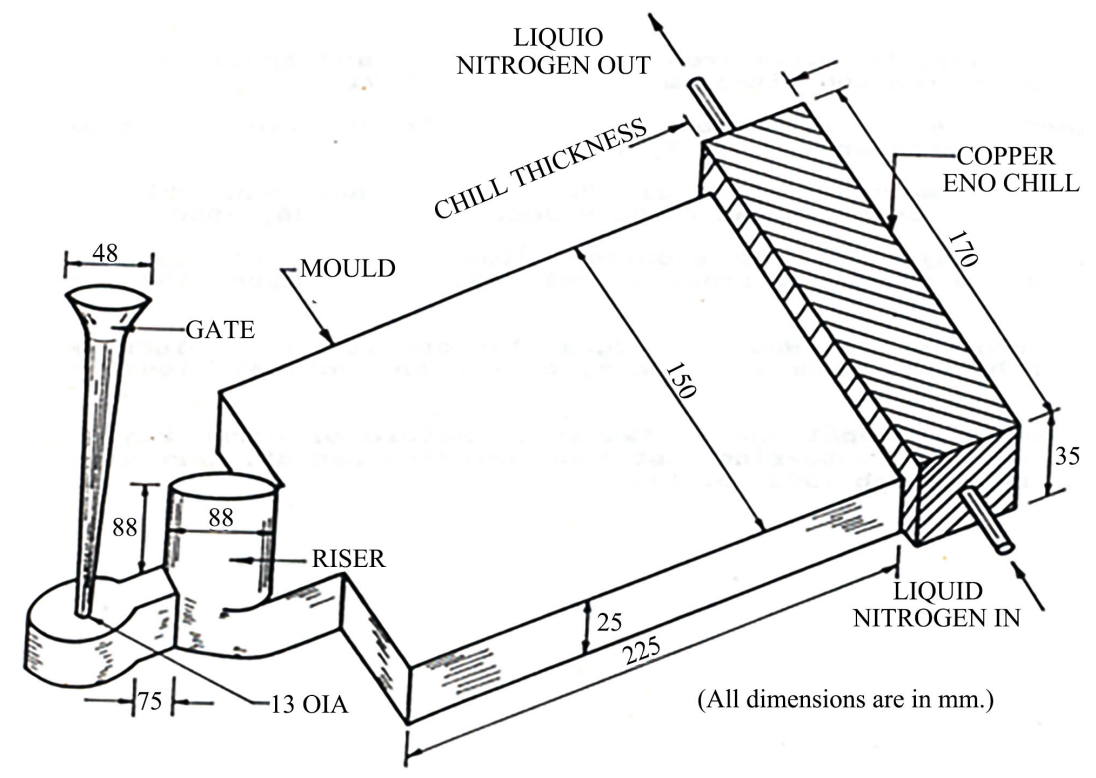

Figure 1. Experimental setup for production of chilled composite.

LM-13 aluminum alloy was melted in an induction furnace and when the melt was superheated to $720^{\circ} \mathrm{C}$ to which the reinforcement was added for $3 \mathrm{wt} \%$ to 12 $\mathrm{wt} \%$ in steps of $3 \mathrm{wt} \%$ and stirred with an impeller rotating at $350 \mathrm{rpm}$. Finally it was taken into a preheated ladle containing calcium silicide (which acts as deoxidizing agent) during pouring. This $\mathrm{TiC}$ reinforcement treated molten composite was then poured into the mold containing different end chills. After solidification all the test castings were heat treated (aging) for 5 hours and finally these castings were cleaned and cut to prepare specimens. Chemical composition and properties of LM-13 $\mathrm{Al}$ alloy used in the present investigation is shown in Table 1 and Table 2 and properties of TiC in Table 3.

TiC was purchase from "Amorphous Materials Ltd., England and LM-13 aluminum alloy from "Hindustan Metallurgicals", India.

\subsection{Testing}

\subsubsection{Metallographic Examination}

The specimens for micro structural studies were polished according to ASTM metallurgical standards and fine polishing was done using alumina powder and diamond paste. The specimens were etched with $3 \%$ Nital to evolve grain boundaries. Micro-structural studies were done using Olympus optical metallurgical microscope. SEM (Jeol make) was used to study the fractured surface in tension test and wear morphology of the worn surface.

\subsubsection{Tensile and Hardness Tests}

Tension tests were conducted at ambient temperature $\left(26^{\circ} \mathrm{C}\right)$ on computerized universal testing machine of 60 ton capacity in the load range of $0-600 \mathrm{kN}$. The specimens for mechanical tests were taken at three different locations along the length of the casting (at $15 \mathrm{~mm}, 110 \mathrm{~mm}$ and $210 \mathrm{~mm}$ from chill end) and were 
Table 1. Chemical composition of the matrix alloy (LM 13).

\begin{tabular}{cccccccc}
\hline Elements & $\mathrm{Zn}$ & $\mathrm{Mg}$ & $\mathrm{Si}$ & $\mathrm{Ni}$ & $\mathrm{Fe}$ & $\mathrm{Mn}$ & $\mathrm{Al}$ \\
\hline by wt\% & 0.5 & 1.0 & 12 & 2.0 & 0.5 & 1.0 & $\mathrm{Bal}$ \\
\hline
\end{tabular}

Table 2. Properties of LM-13 aluminum alloy.

\begin{tabular}{cccccc}
\hline Property & UTS (MPa) & $\begin{array}{c}\text { Hardness } \\
(\mathrm{HRB})\end{array}$ & $\begin{array}{c}\text { Melting point } \\
\mathrm{O}^{\circ} \mathrm{C}\end{array}$ & $\begin{array}{c}\text { Density } \\
(\mathrm{gm} / \mathrm{cc})\end{array}$ & Structure \\
\hline 155 & 150 & 698 & 2.7 & FCC \\
\hline
\end{tabular}

Table 3. Properties of titanium carbide (TiC).

\begin{tabular}{ccccc}
\hline $\begin{array}{c}\text { Density } \\
\mathrm{g} / \mathrm{cc}\end{array}$ & $\begin{array}{c}\text { Hardness } \\
(\text { HRB })\end{array}$ & $\begin{array}{c}\text { Melting point } \\
\left({ }^{\circ} \mathrm{C}\right)\end{array}$ & $\begin{array}{c}\text { Type of } \\
\text { Structure }\end{array}$ & Color \\
4.93 & 280 & 3160 & Cubic & Black \\
\hline
\end{tabular}

prepared according to AFS standards. Rockwell hardness (HRB) for the samples was measured using ZWICK-Roll ZHR hardness tester with a load of $100 \mathrm{~kg}$-f using ball indenter of size 1/16 inch in diameter. The values reported in both these tests are the average of three repetitions on the same sample at the same location.

\subsubsection{Tribological Test}

Wear test for the samples are conducted using pin on disc computerized DUCOM make sliding wear testing machine. The specimen is a pin of size $6 \mathrm{~mm}$ in diameter and $25 \mathrm{~mm}$ long where as the disc is of alloy steel having hardness of HRC 62. Before the test the surface of the pin was cleaned with acetone and volume loss method (LVDT attached to the specimen to measure change in length) was adopted in the present investigation. Test was carried out by applying normal load on pin from 10 to $30 \mathrm{~N}$ in steps of $10 \mathrm{~N}$ at different disc speeds.

\section{Results and Discussions}

\subsection{Micro Structural Observation of the Composite}

\subsubsection{Solidification Pattern}

Figures 2(a)-(c) shows microstructure of the composite using different chills, Figure 2(d) and Figure 2(e) shows eutectic cell count (at low magnification at 50x) and Figure 2(e) and Figure 2(f) shows Dendrite Arm Spacing (DAS) of graphite chilled and copper chilled composite. The differences in associated TiC distribution, its randomness, length and its matrix structure (as shown in Figures 2(a)-(c)) for the various specimens cast were analyzed and correlated to the temperature of eutectic formation. Faster cooling produces fine, highly oriented dendrites, while slow cooling produces large, coarse dendrites. Solidification over a temperature range is the primary requirement for dendrite growth. Pri- 
mary austenite dendrites readily grow from the liquidus down to the eutectic temperature. Growth of dendrites may also continue concurrently with the eutectic as the temperature decreases through eutectic range to the solidus. Thus, under cooling in case of copper chilled composite may lead to longer dendrites and higher interaction. Hence, the eutectic cells solidify around these austenite dendrites and in this manner the entire microstructure is affected by the number and size of the dendrites.

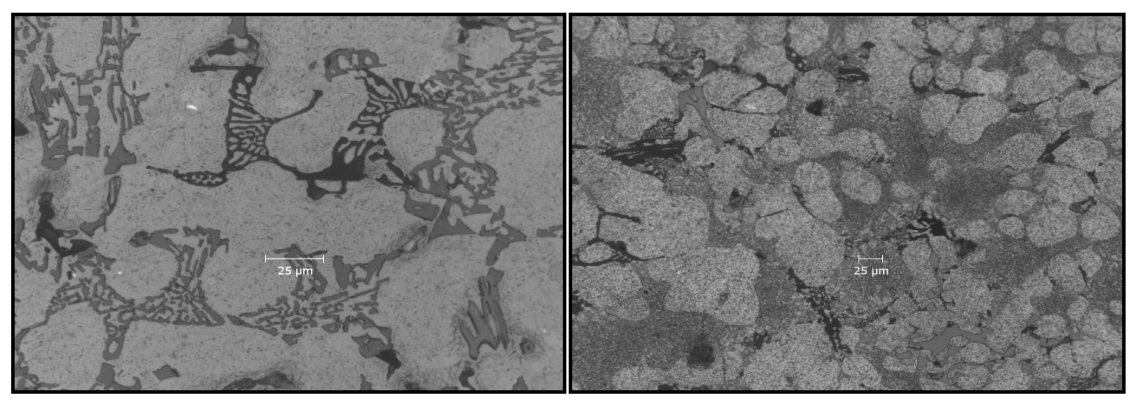

(a) Copper chilled (500x)

(b) Graphite chilled (500x)

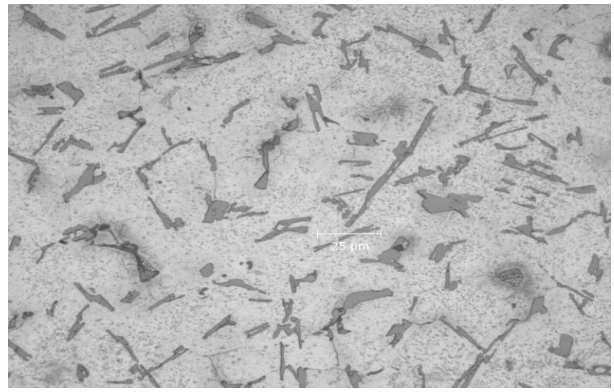

(c) Matrix alloy (LM-134)

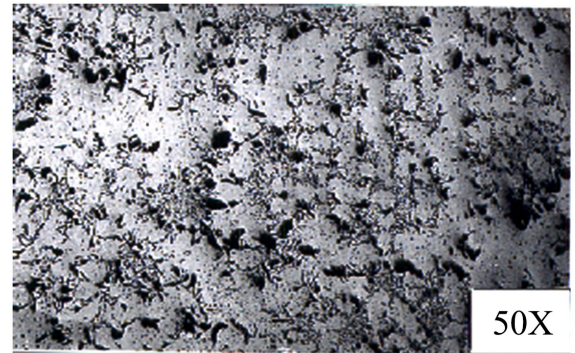

(d) Copper chilled composite

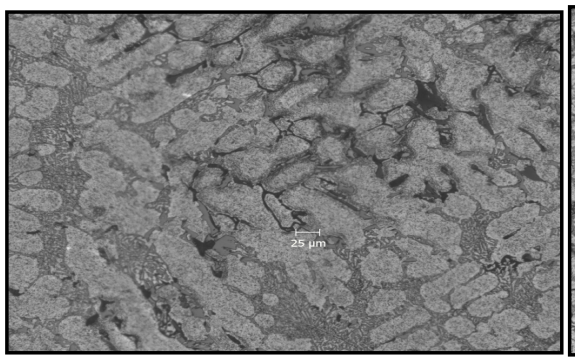

(f) Graphite chilled (500×)

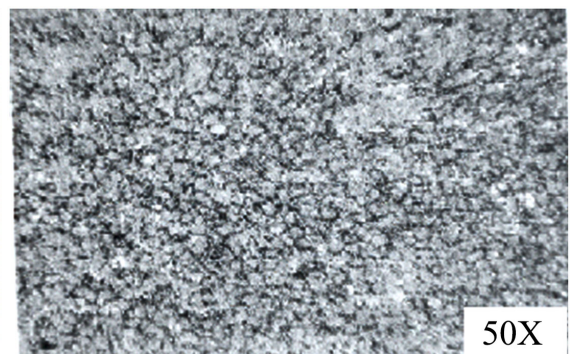

(e) Graphite chilled composite

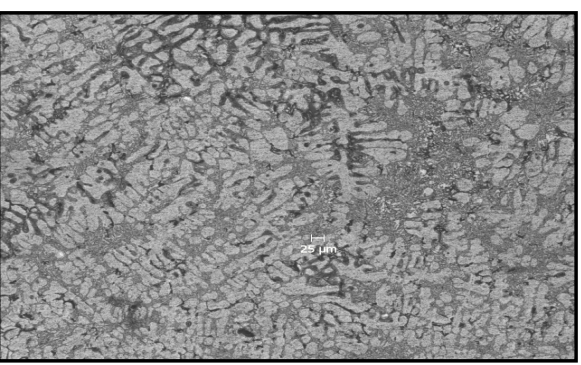

(g) Copper chilled $(500 \times)$

Figure 2. Microstructure (a to c), eutectic cell ( $\mathrm{d}$ and e) and dendrite arm spacing ( $\mathrm{f}$ and g) of different composites (9 wt\% reinforcement). 
Therefore the general picture of solidification of graphite chilled (non metallic) composite and copper chilled composite (metallic) with various eutectic cells, dendrite arm spacing, graphite shapes and matrix structures (as shown in Figures 2(a)-(g)) can be summarized as follows: The solidification of the composite resulting from sand casting without a chill starts from a small number of nuclei as compared with chilled composites, a phenomenon indicated by eutectic cell count (see Figure 2(d) and Figure 2(e)). Since the growth condition in the liquid are favorable, these nuclei start growing as soon as temperature below the equilibrium temperature in case of graphite chilled MMC and with maximum under cooling in the case of copper chilled composite.

\subsubsection{Dendrite Formation}

Results of the investigation indicate that the minimum eutectic temperature can be used as a measure of under-cooling that reflects DAS (Figure 2(f) and Figure $2(\mathrm{~g})$ ), the number of cells (Figure 2(d) and Figure 2(e)) precipitated and the chilling tendency of the composite. Higher dendritic interaction areas in the case of chilled composites reflect the interweaving of dendrite through eutectic cells that effectively tie the eutectic cells together. Since dendrites are formed from primary eutectic phase, they have a higher tensile strength. Here, due to chilling, nucleation and dendrites directly form from the melt.

\subsection{Mechanical Behavior (Strength and Hardness) of Composite}

Table 4 and Table 5 shows the results of mechanical properties (UTS and hardness) of various chilled composites developed. From Table 4 and Table 5 it is observed that addition of reinforcement beyond $9 \mathrm{wt} \%$ do not improve mechanical properties and hence further discussions will be based on the composite containing $9 \mathrm{wt} \%$ reinforcement. Results of mechanical properties indicate that strength and hardness both depends on the type of chill used for casting as well as the reinforcement content present. It is also observed from Table 4 and Table 5 that strength and hardness of the composite (containing $9 \mathrm{wt} \%$ reinforcement) cast with copper chill is found to be superior compared to graphite chilled composites. Improvement in strength and hardness in the case of copper chilling is because of high volumetric heat capacity (VHC) of the chill which has resulted in fine grain structure of the matrix (see Figure 2(a)) during solidification and the reinforcement content in the composite. It is finally observed that addition of $9 \mathrm{wt} \%$ reinforcement to $\mathrm{Al}$ alloy (LM-13) matrix and copper chilling increases the strength by $11.6 \%$ and hardness by $21.3 \%$ near the chill end. Note that UTS and hardness of LM-13 Al alloy are $155 \mathrm{~N} / \mathrm{mm}^{2}$ (Mpa) and $150 \mathrm{HRB}$ respectively.

Figure 3(a) and Figure 3(b) shows SEM fractographs of copper chilled and graphite chilled specimens failed in tension testing. It is seen from the fractographs that copper chilled composite has fine grain structure with large dimples as compared with graphite chilled MMC which has shallow dimples. It is also observed that the mode of fracture has changed from moderately ductile graphite chilled) to cleavage in the case of copper chilled composite. 
Table 4. UTS (Mpa) of various chilled composites developed.

\begin{tabular}{ccccc}
\hline wt\% reinforcement & 3 & 6 & 9 & 12 \\
\hline Copper chilled & 163 & 169 & 173 & 170 \\
Graphite chilled & 152 & 155 & 161 & 160 \\
\hline
\end{tabular}

Table 5. Hardness (HRB) of various chilled composites developed.

\begin{tabular}{ccccc}
\hline wt\% reinforcement & $\mathbf{3}$ & $\mathbf{6}$ & 9 & 12 \\
\hline Copper chilled & 163 & 171 & 182 & 181 \\
Graphite chilled & 159 & 163 & 170 & 170 \\
\hline
\end{tabular}

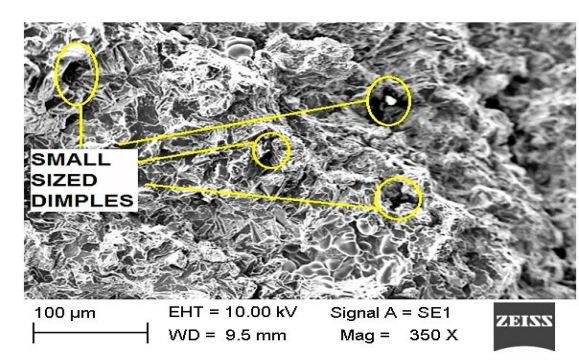

(a) Copper chilled composite

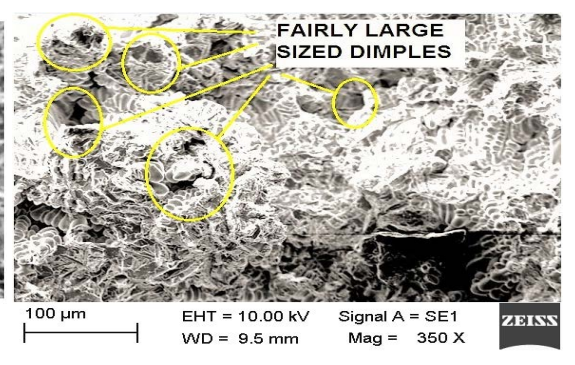

(b) Graphite chilled composite

Figure 3. SEM of fractured surface of composite ( $9 \mathrm{wt} \%$ reinforcement) failed in tension.

\subsection{Tribological Behavior of the Composite}

Results of mechanical properties of the chilled composite developed indicate that, hardness was maximum in the case of composite containing $9 \mathrm{wt} \%$ reinforcement hence all further discussions will be based on this chilled composite.

\subsubsection{Relationship between Microstructure and Wear}

In the two body abrasion, the major portion of the load applied during testing is transferred to the specimen and the wear of the material took place under high stress condition [12]. This is supported by the experimental results, as evident by the increase in transition load from severe to mild wear with the chilling rate [13]. These explanations are in line with earlier reports of Moustafa [14] that have shown an increase in the load for transition from mild to severe wear.

The hard $\mathrm{TiC}$ reinforcement particles in chilled composite act as protuberances in the aluminum matrix and bear the major portion of load and as a consequence, protect the composite from wear. This leads to the reduction of wear rate of chilled composites due to reinforcement of TiC particles in the matrix of al alloy. The wear rate is significantly dependent on the applied load, microstructure and hardness of the material. The cutting efficiency of the disc particles increases with an increase in the applied load. As a result, more material is removed at higher loads and hence the wear rate increases with an applied load. The depth and width of cutting grooves also depends on the hardness of the material [15]. The hardness of the graphite chilled composite is lower than that of the copper chilled composites and hence, the wear rate of chilled composites 
becomes lower than that of the graphite chilled composite. Therefore, the chances of fracturing of $\mathrm{TiC}$ particles in the matrix are less in the case of copper chilled composites. This led to considerably higher wear resistance of the copper chilled composites even at a high load regime. As a result, the removal of a material vis-à-vis the wear rate of the material is governed by deformation parameters, microstructure and hardness. Thus by increasing the strength and hardness between matrix (effect of chilling) and the presence TiC particles, the cutting efficiency of the hard disc particles is reduced.

\subsubsection{Relationship between Load, Hardness and Wear}

It is well known that the wear rate of the material decreases with hardness irrespective of the applied load. SEM studies of the copper chilled composites tested at different loads reveal that, at lower load $(10 \mathrm{~N})$, the variation of wear rate with hardness was marginal, but at higher load $(30 \mathrm{~N})$ considerable wear with hardness was noted. At lower load, mainly cutting type wear takes place and the subsurface deformation is negligible [16]. The TiC particles remain intact within the matrix alloy and protect the specimen surface more effectively. Thus, at lower load, the surface deformation behavior is negligible. At higher load, both cutting and ploughing types of mechanisms are operating and the subsurface deformation becomes considerably high. Because of subsurface deformation, transverse and longitudinal cracks are generated on the wear surface [17]. Subsequently, because of cold working, the subsurface is also working hardened [18]. The subsurface deformation is governed by the mechanical properties such as hardness, ductility and strength, which are again influenced by the microstructure and distribution of hard $\mathrm{TiC}$ particles. These may cause considerable reduction in the wear rate with an increase in hardness and strength when tests are conducted at higher applied load. The sub surface deformation of the graphite chilled composite may vary because of different matrix micro-structure and mechanical properties. In addition to the initial hardness of the copper chilled composite, after a few cycles of motion of the sample against the abrasive media, the hardness of the wear surface of different samples increases. Apart from this, since the $\mathrm{TiC}$ particles are very fine and they may have the tendency to break into small particles and spread over the wear surface thus protecting the matrix alloy from severe wear.

\subsubsection{Friction and Wear}

Results of the wear test shows the variation in volume loss of the composite as a function of sliding distance tested at loads 10,20 and $30 \mathrm{~N}$ respectively. At the lowest load $(10 \mathrm{~N})$ in mild wear regime with a high coefficient of friction was always found for all the chilled composites tested. At higher loads $(30 \mathrm{~N})$, the copper chilled composites exhibited severe wear with a better wear resistance than the graphite chilled composite. However, graphite chilled composite tested at all loads underwent large volume loss during the early stages of the test. After sliding for some distance, the volume loss increased approximately linear with 
sliding distance. The sliding distance for transition from severe to mild wear could be identified by two factors: Firstly, by abrupt and steep reduction in the frictional force, and secondly, by change in the magnitude of displacement of pin specimen [19]. Based on these measurements, the wear curves are characterized by two distinct lines of different slopes, which correspond to severe and mild wear conditions. Composite, cast using copper chill showed steady state mild wear from the beginning of the test. At no point during the tests was severe wear noticed. It was also observed that, the sliding distance and volume loss during the severe wear regime decreases with an increase the chilling rate. In the case of composites cast with copper chill, severe wear did not occur at all. These wear rates in the severe wear regime was calculated by dividing the volume loss by the sliding distance of severe wear. In the severe wear regime, wear rates of composites decrease with increasing the chilling rate. The transition to lower wear rates (mild wear regime) is accelerated with increasing in heat capacity of the chill. It is obvious that chilling effectively prevents the time/distance required for transition from severe to mild wear.

The mean steady state values of the coefficient of friction $(\mu)$ as a function of sliding speed tested at loads 10,20 and $30 \mathrm{~N}$ are studied for both the graphite chilled and the copper chilled composites. At the lowest applied load of $10 \mathrm{~N}$ and at the lowest sliding speed of $0.3 \mathrm{~m} / \mathrm{sec}$ a very high coefficient of friction about 1.0 was measured for the graphite chilled composite in the mild wear regime and for the copper chilled composites it was reduced to around 0.76. At intermediate sliding speed $(1.2 \mathrm{~m} / \mathrm{sec})$ the coefficient of friction decreases in the mild wear regime and finally at higher sliding speeds $(1.8 \mathrm{~m} / \mathrm{sec})$ all the steels displayed the same frictional behavior with coefficient of friction value around 0.55 . With an applied load of $20 \mathrm{~N}$ and at the lowest sliding speed a high coefficient of friction of 0.92 was measured for the graphite chilled composite in the mild wear regime, whereas for the copper chilled composites it was decreased to $0.7-0.87$. At the highest applied load of $30 \mathrm{~N}$ and at the lowest sliding speed a high coefficient of friction of 0.9 was measured for the graphite chilled composite which displayed a mild wear regime, whereas the copper chilled composites at the same sliding speed was decreased down to $0.6-0.8$. At intermediate sliding speed the trend is that, a high coefficient of friction was measured in the mild wear regime and decrease to lower values of $0.35-0.5$. At the highest sliding speed all the chilled composites displayed the same frictional behavior with a lower value of coefficient of friction around 0.55 independently from the applied load the wear regime.

\subsubsection{SEM Analysis of the Worn Surface}

Figure 4(a) and Figure 4(b)) shows SEM photograph of the worn surfaces of the graphite chilled and copper chilled composites in the mild wear regime. It is observed that for the composite cast using graphite chill, worn surface was completely smooth and flat and contained wear tracks in the direction of sliding. In addition, the signature of plastic flow is not at all observed in the subsurface. In 


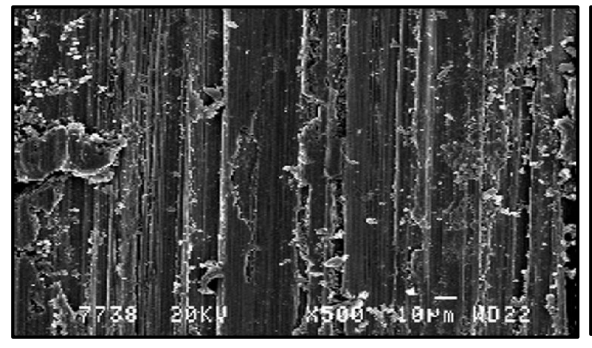

(a) Copper chilled $(100 \mu \mathrm{m})$

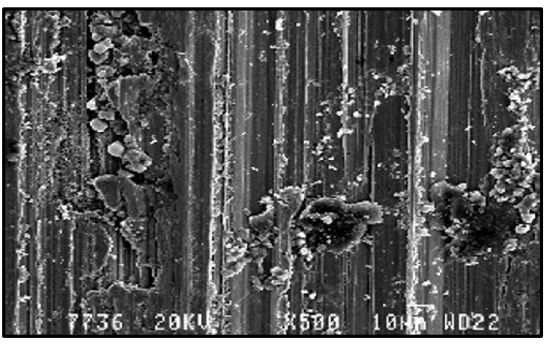

(b) Graphite chilled $(100 \mu \mathrm{m})$

Figure 4. SEM photomicrograph of worn surface of various composites (9 $\mathrm{wt} \%$ reinforcement) in the mild wear regime.

contrast, the worn surface of composite cast using copper chill was found to be rough. Microscopic examination of its subsurface shows fragmentation and their uniform dispersion on the entire worn surface and, as a result, plastic flow is very limited. Further, in the case of copper chilled composite, the surface found to be very rough with a characteristic brittle fracture. The subsurface region consisted of fragments of crushed TiC (indicated by an arrow in Figure 4(b)). This shows that mild wear is dominated in composite cast using copper chill. A very thin tribo-induced layer was formed on the entire surface and, in addition some $\mathrm{TiC}$ particle was projected onto the surface. The lengths of the crushed TiC particles were measured for more than 10 fragments on the several cross sectional micrographs. The mean length was found to be $8 \mu \mathrm{m}$ (ranging from 4.5 to 12 $\mu \mathrm{m})$ for copper chilled composites. From these detailed observations, it becomes obvious that the reinforcement present were crushed into small fragments and a thin layer is formed on the smooth surface containing wear tracks confirming abrasive wear in the mild wear regime.

\section{Summary and Conclusions}

In this research, characterization of wear behavior of graphite chilled composites and copper chilled composites cast using high rate heat transfer during solidification was studied. The results can be summarized as follows.

1) Microstructure of the copper chilled composite is finer than that of the graphite chilled composite with random orientation of $\mathrm{TiC}$ particles in matrix alloy.

2) Strength, hardness and wear resistance of the copper chilled composites are superior to those of the graphite chilled composites. It was found that these properties increase with an increase in $\mathrm{TiC}$ particles in fine chilled matrix alloy.

3) At lower load copper chilled composites exhibited mild wear regime with high coefficient of friction and at higher loads they exhibited severe wear with better wear resistance than the graphite chilled composite.

4) Size of the wear debris decreases because of rapid crack propagation of a brittle body under compression whereas the size of the TiC fragmentation remains approximately the same. 


\section{Conflicts of Interest}

The authors declare no conflicts of interest regarding the publication of this paper.

\section{References}

[1] Hemanth, J. (2003) Effect of High Rate of Heat Transfer during Solidification of Alloyed Cast Iron Using Water-Cooled and Sub-Zero Chills on Mechanical Behaviour. Materials and Design, 24, 37-45. https://doi.org/10.1016/S0261-3069(02)00086-9

[2] Huang, J.Y., Liao, X.Z., et al. (2003) Microstructure of Cryogenic Treated M2 Tool Steel. Materials Science and Engineering A, 339, 241-244. https://doi.org/10.1016/S0921-5093(02)00165-X

[3] Collins, D.N. and Dormer, J. (1997) Deep Cryogenic Treatment of a D2 Cold Work Tool Steel. Heat Treatment of Metals, 3, 71-74.

[4] Barron, R.F. (1973) Effect of Cryogenic Treatment on Lathe Tool Wear. Progress in Refrigeration Science and Technology, 1, 529-533.

[5] Meng, F. and Tagashira, K. (1994) Wear Resistance and Microstructure of Cryogenic Treated Fe-1.4Cr-1C Bearing Steel. Scripta Metallurgica et Materialia, 31, 865-868. https://doi.org/10.1016/0956-716X(94)90493-6

[6] Bensely, A., Prabhakaran, A., Mohan Lal, D. and Nagarajan, G. (2006) Enhancing the Wear Resistance of Case Carburized Steel (En353) by Cryogenic Treatment. Cryogenics, 45, 747-754. https://doi.org/10.1016/j.cryogenics.2005.10.004

[7] Raza Batne, M., Szpuran, J.A., Wang, X. and Li, D.Y. (2006) Wear and Corrosion Wear of Medium Carbon Steel. Wear, 260, 116-122.

https://doi.org/10.1016/j.wear.2004.12.037

[8] Chen, Z., Tang, J., Chen, G. and Yan, H. (2007) Effect of Si Content and Thermo-Mechanical Treatment on Dry Sliding Wear Behavior. Wear, 262, 362-368. https://doi.org/10.1016/j.wear.2006.05.019

[9] Ahmed, S., Haseeb, A.S.M.A. and Kurny, A.S.W. (2007) Study of Wear Behavior of $\mathrm{Al}-4.5 \% \mathrm{Cu}-3.4 \% \mathrm{Fe}$ in Situ Composite. Journal of Materials Processing Technolo$g y$, 182, 327-332. https://doi.org/10.1016/j.jmatprotec.2006.08.009

[10] Hemanth, J. (1996) Wear Characteristics of Sub Zero Chilled Cast Iron. Wear, 192, 134-143. https://doi.org/10.1016/0043-1648(95)06781-7

[11] Hemanth, J. (1998) Effect of Cooling Rate on the Dendrite Arm Spacing and Ultimate Tensile Strength of Cast Iron. Material Science, 33, 23-35.

[12] Iwai, Y. and Honda, H. (1995) Sliding Wear Behavior of SiC Whisker Reinforced Al Composites. Wear, 181, 594-602. https://doi.org/10.1016/0043-1648(95)90175-2

[13] Mondal, D.P., Das, S. and Jha, A.K. (1998) Abrasion Wear of Al Based Composites. Wear, 223, 131-139. https://doi.org/10.1016/S0043-1648(98)00278-6

[14] Moustafa, S.F. (1995) Wear and Wear Mechanism of $\mathrm{Al}-22 \% \mathrm{Si} / \mathrm{Al}_{2} \mathrm{O}_{3}$ Composites. Wear, 95, 185-198. https://doi.org/10.1016/0043-1648(95)06607-1

[15] Wang, A.G. and Hutchings, I.M. (1989) Wear of Alumina-Fibre Aluminum Composites. Materials Science and Technology, 5, 71-84. https://doi.org/10.1179/026708389790337503

[16] Wang, A. and Rack, H.J. (1991) Friction Behavior of Al-SiCp Composites. Wear, 146, 337-344. https://doi.org/10.1016/0043-1648(91)90073-4 
[17] Moore, M.A. and Douthwaite, R.M. (1976) Tribological Behavior of Ceramic Based Composites. Metallurgical and Materials Transactions A, 7, 1833-1842. https://doi.org/10.1007/BF02654978

[18] Prasad, B.K., Modi, O.P. and Jha, A.K. (1994) Metallurgical Aspects of Al Based Composites. Tribology International, 27, 153-158.

https://doi.org/10.1016/0301-679X(94)90039-6

[19] Venkataraman, B. and Sundarajan, G. (1996) The Sliding Wear Behavior of Al-SiC Particulate Composites. Acta Materialia, 44, 451-462.

https://doi.org/10.1016/1359-6454(95)00217-0 